\title{
PROJETO SABERES DA MATA ATLÂNTICA: PERCEPÇÃO AMBIENTAL E CIENTÍFICA DE ESTUDANTES DO ENTORNO DO PARQUE ESTADUAL DA SERRA DO BRIGADEIRO (MG)
}

\author{
Ana Paula Agrizzi 1 \\ Marcos da Cunha Teixeira ${ }^{2}$ \\ Iorrana Vieira Salustiano ${ }^{3}$ \\ Laís Azevedo Rodrigues ${ }^{4}$ \\ Alisson Andrade Almeida ${ }^{5}$ \\ Isabella Oliveira Britto ${ }^{6}$ \\ Jordana Luizi dos Prazeres ${ }^{7}$ \\ Rafael Mendes Teixeira ${ }^{8}$ \\ João Paulo Viana Leite ${ }^{9}$
}

Resumo: Objetivou-se analisar a percepção de estudantes da educação básica de quatro escolas públicas do entorno do Parque Estadual da Serra do Brigadeiro sobre o bioma Mata Atlântica. Adotando-se abordagem de pesquisa mista, utilizou-se evocação livre e aplicação de questionário para 150 estudantes. Os dados, submetidos à análise de conteúdo, revelaram a existência de percepção equivocada quanto a aspectos geográficos e de conservação da Mata Atlântica. Embora os estudantes tenham apresentado conhecimento acerca de espécies nativas, também relacionaram espécies exóticas ao bioma. Sugere-se o desenvolvimento de abordagens pedagógicas formais e não-formais baseadas na Educação Ambiental biorregionalista.

Palavras-chave: Percepção; Educação Ambiental; Divulgação Científica; Biorregionalismo.

\footnotetext{
${ }^{1}$ Universidade Federal de Viçosa. E-mail: agrizzianapaula@gmail.com

2 Universidade Federal do Espírito Santo. marcosteixeiraufes@gmail.com

3 Universidade Federal de Viçosa. E-mail: iovieirasalus@gmail.com

${ }^{4}$ Universidade Federal de Viçosa. E-mail: lala-rodrigues@hotmail.com

${ }^{5}$ Universidade Federal de Viçosa. E-mail: alisson.almeidaufv@gmail.com

${ }^{6}$ Universidade Federal de Viçosa. E-mail: isabellaaobrittoo@gmail.com

7 Universidade Federal de Viçosa. E-mail: jordanaluizi@gmail.com

8 Universidade Federal de Viçosa. E-mail: rafaelmttur@hotmail.com

9 Universidade Federal de Viçosa. E-mail: jpvleite@ufv.br
} 
Abstract: The objective was to analyze the perception of students in basic education from four public schools around the Serra do Brigadeiro State Park about the Atlantic Forest Biome. Adopting the mixed research approach, free recall and questionnaire were used for 150 students. The data, submitted to content analysis, revealed the existence of a mistaken perception regarding the geographic and conservation aspects of the Atlantic Forest. Although the students presented knowledge about native species, they also related exotic species to the biome. Suggestion has been made for the development of formal and non-formal pedagogical approaches based on bioregionalist Environmental Education.

Keywords: Perception; Environmental education; Scientific Dissemination; Bioregionalism.

\section{Introdução}

A partir da Revolução Industrial o meio ambiente tem sofrido com a intensificação das atividades humanas. Ao longo desses anos, a exploração e transformação dos recursos naturais tornaram-se preocupantes. No Brasil, um dos biomas mais impactados é a Mata Atlântica, que desde o início da colonização, tem sido palco de intenso povoamento humano e exploração de sua biodiversidade (DEAN, 2004).

A Mata Atlântica é um dos principais biomas mundiais, sendo constituído por um agregado de ecossistemas e formações florestais como manguezais, restingas e campos de altitude. É considerada a segunda maior floresta tropical do continente americano e abriga uma diversidade de espécies por área superior à da Floresta Amazônica. Além disso, por ser uma área considerada de grande diversidade biológica, compreendendo de 1 a $8 \%$ da biodiversidade mundial, está classificada entre os 34 hotspots do planeta (JOLY; METZGER; TABARELLI, 2014; EISENLOHR et al., 2013; MYERS et al., 2000; SOSMA, 2009). Apresenta altos índices pluviométricos e grandes variações no relevo, características que contribuem para a megadiversidade e altos níveis de endemismo encontrados no bioma (OLIVEIRA-FILHO; FONTES, 2000; SILVA et al., 2003). Demasiadamente ameaçada, a conservação dos remanescentes de Mata Atlântica e a recuperação da sua vegetação nativa são esforços fundamentais para a manutenção do conjunto de ecossistemas encontrado neste bioma (SILVA et al., 2016).

Há uma divergência entre os autores sobre o percentual de cobertura vegetal remanescente da Mata Atlântica, de acordo com a metodologia utilizada. Grande parte das estimativas variam de 11 a $16 \%$ de floresta nativa (RIBEIRO et al., 2009; RIBEIRO et al., 2011). Contudo, segundo relatório publicado pela Fundação SOS Mata Atlântica em conjunto com o Instituto Nacional de Pesquisas Espaciais (INPE), que há 29 anos mapeia o bioma Mata Atlântica, atualmente 0 remanescente de floresta totaliza $12,4 \%$. O mapeamento, realizado no período de 2017-2018, inclui tanto as áreas maiores 
presentes principalmente em Unidades de Conservação quanto os fragmentos de floresta a partir de 3 hectares (SOSMA; INPE, 2019). O Sistema Nacional de Unidades de Conservação da Natureza (SNUC) é constituído pelo conjunto das Unidades de Conservação federais, estaduais e municipais, e é uma relevante estratégia para conservação da Mata Atlântica (BRASIL, 2000). Considerando áreas de proteção integral e de uso sustentável, existem atualmente 1.437 unidades do bioma, que correspondem a apenas $9,1 \%$ do total remanescente de floresta (BRASIL, 2000; SILVA et al., 2016).

Entre as Unidades de Conservação para proteção da Mata Atlântica está o Parque Estadual da Serra do Brigadeiro (PESB). Criado no ano de 1996, o PESB está localizado na Zona da Mata do estado de Minas Gerais, ocupando - extremo norte da Serra da Mantiqueira, nos municípios de Araponga, Fervedouro, Miradouro, Ervália, Sericita, Pedra Bonita, Muriaé e Divino (IEF, 2020). O PESB abrange 14.984 hectares compostos por matas, montanhas, vales, chapadas, encostas e inúmeras nascentes que contribuem de maneira significativa para a formação de duas importantes bacias hidrográficas: a do rio Doce e a do Paraíba do Sul (IEF, 2020). Dentre as atividades desenvolvidas no PESB destacam-se as ações de Educação Ambiental voltados para a conservação da biodiversidade.

No processo educativo para a construção de uma visão crítica da relação homem-natureza e na implementação de ações de conservação da biodiversidade da Mata Atlântica, a Educação Ambiental tem se destacado. Compreende um campo do conhecimento que, com os princípios e valores necessários ao processo, tem como propósito estabelecer uma "nova aliança" entre humanidade e natureza que não seja sinônimo de autodestruição (REIGOTA, 1995). Com o intuito de sensibilizar a sociedade quanto aos problemas ambientais, a Educação Ambiental é importante na promoção de mudanças de hábitos e de comportamentos prejudiciais ao meio ambiente (DIAS, 2004; NUNES; FRANÇA; PAIVA, 2017). Além disso, contribui para uma formação crítica necessária para 0 enfrentamento das questões socioambientais promovidas pelo modelo de desenvolvimento vigente (LOUREIRO, 2006; LAYRARGUES; LIMA, 2014).

A relevância da Educação Ambiental como elemento identitário capaz de desenvolver uma educação crítica, ética e emancipatória é atualmente reconhecida no Brasil. Por meio da Lei $n^{\circ} 9.795$ de 27 de abril de 1999, que estabelece a Política Nacional de Educação Ambiental, regulamentada pelo Decreto 4.281/2002 a Educação Ambiental está institucionalizada no país (BRASIL, 1999; BRASIL, 2002). Em sua essência, trata-se da consolidação de um processo de inclusão da dimensão ambiental na educação que ganhou força no Brasil com a promulgação da Constituição da República de 1988. Nesta, um capítulo inteiro foi destinado ao Meio Ambiente (Capítulo VI, do Título VIII) e tratou da Educação Ambiental em seu art. 225, $\S 1^{\circ}$, VI deixando explícito que incumbe ao "Poder Público sua promoção em todos os níveis de ensino" (BRASIL, 1988). 
Segundo Quarterzani, Agrizzi e Teixeira (2016, p. 7.553) "um dos princípios da Educação Ambiental é a inserção dos aspectos socioambientais locais nos processos educativos, visando o desenvolvimento do sentimento de pertencimento dos sujeitos com o local em que vivem". Numa visão biorregional "[...] o lugar é definido pelas suas formas de vida, pela topografia e pela biota e não por leis editadas pelos seres humanos" (COUSIN, 2004, p. 23). Quaterzani, Agrizzi e Teixeira (2016, p. 7.553) afirmam que "essa linha de pensamento tem sido estudada pela teoria do biorregionalismo" e que ela "busca restabelecer uma conexão entre as comunidades humanas de uma determinada região com seu ambiente natural'. Conforme explica Gonzalez (2006, pp. 56-57), biorregião significa, etmologicamente, "região com vida", sendo um espaço que difere de outros ambientes por seus atributos naturais e culturais que se integram e se manifestam em equilíbrio.

O projeto de extensão "Saberes da Mata Atlântica" tem atuado nesta perspectiva biorregionalista no território da Serra do Brigadeiro. Com o apoio financeiro da FAPEMIG (Edital de Popularização da Ciência, Tecnologia e da Inovação), o projeto faz parte das ações de popularização da ciência do grupo de pesquisa Bioprospecção Molecular no Uso Sustentável da Biodiversidade (BIOPROS) da Universidade Federal de Viçosa (UFV). Proporcionando a interação entre pesquisadores e a comunidade escolar daquela biorregião, o projeto consiste em expedições itinerantes, compostas por um caminhãocinema para projeção de documentário sobre a Mata Atlântica, oficinas e atividades lúdicas e apresentação das pesquisas realizadas pelo BIOPROS. As atividades acontecem em escolas do entorno do PESB, empregando uma abordagem científica e educativa que visa, para além da Educação Ambiental e divulgação científica, despertar o sentido de pertencimento de educandos e educadores ao ambiente natural em que vivem.

Contudo, o estudo da percepção ambiental e compreensão entre a relação homem e ambiente, engloba as expectativas, satisfações, condutas e julgamentos, que uma comunidade possui sobre o ambiente onde vive (FERNANDES et al., 2004). Portanto, o conhecimento adquirido sobre a relação do público da presente pesquisa com o bioma Mata Atlântica poderá reorientar as ações de intervenção pedagógica do projeto e, assim, influenciar na ressignificação da percepção sobre o bioma.

Nessa perspectiva, pode-se afirmar que a importância de pesquisas em percepção ambiental deve-se ao fato de ser uma investigação da relação do homem e seu meio vivencial (RIO; OLIVEIRA, 1999). Corroborando essa ideia, na década de 1970 a UNESCO, em seu programa "Homem e biosfera", preconiza o estudo da percepção ambiental como uma contribuição fundamental para uma gestão mais harmoniosa dos recursos naturais. De acordo com a UNESCO (1975), uma das dificuldades para a conservação de ambientes naturais está presente nas várias percepções e valores que são atribuídos ao ambiente entre indivíduos de culturas e classes sociais diferentes. A análise da percepção ambiental constitui, ainda, uma estratégia 
recomendada pela Política Nacional de Educação Ambiental (PNEA) a ser utilizada nos diagnósticos socioambientais locais.

Assim, no presente estudo objetivou-se analisar as percepções ambientais e científicas sobre o bioma Mata Atlântica de discentes do ensino fundamental, médio e da modalidade Educação de Jovens e Adultos (EJA) de escolas na biorregião da Serra do Brigadeiro.

\section{Materiais e Métodos}

Neste trabalho foi adotada a modalidade de pesquisa mista, que utiliza, concomitantemente, os princípios das abordagens quantitativa e qualitativa (CRESWELL, 2010). A abordagem quantitativa tem suas raízes no pensamento positivista lógico e tende a enfatizar os atributos mensuráveis da experiência humana. Para isso, recorre à linguagem matemática para descrever as causas de um fenômeno. Por outro lado, a pesquisa de abordagem qualitativa tende a salientar os aspectos dinâmicos, holísticos e individuais da experiência humana para apreender a totalidade no contexto daqueles que estão vivenciando o fenômeno (POLIT; BECKER; HUNGLER, 2004, p. 201).

A pesquisa ocorreu no mês de junho de 2018, durante expedições do projeto "Saberes da Mata Atlântica", tendo como público estudantes de quatro escolas públicas da região da Serra do Brigadeiro, na Zona da Mata Mineira.

Participaram da pesquisa um total de 150 estudantes de ensino fundamental II e médio, nos quais estão incluídos também estudantes da modalidade EJA. Deste total, $23(15,3 \%)$ são discentes do ensino fundamental II e $127(84,6 \%)$ do ensino médio, conforme distribuição apresentada na Tabela 1 (abaixo). Do total de discentes que participaram da pesquisa, 10\% apresentavam idade superior a 20 anos, 56\% pertenciam à faixa etária entre 16 e 20 anos, e 34\% entre 11 e 15 anos. Quanto ao gênero, 95 (63,4\%) se declararam do sexo feminino e $55(36,6 \%)$ do sexo masculino. 
Tabela 1: Distribuição dos estudantes participantes da pesquisa conforme as etapas e ano.

\begin{tabular}{ccc}
\hline Etapas & Ano & Total de participantes \\
\hline \multirow{4}{*}{ Ensino Fundamental II } & $6^{\circ}$ & 4 \\
\cline { 2 - 3 } & $7^{\circ}$ & 3 \\
\cline { 2 - 3 } & $8^{\circ}$ & 7 \\
\cline { 2 - 3 } Ensino Médio & $9^{\circ}$ & 9 \\
\cline { 2 - 3 } & $1^{\circ}$ & 38 \\
\cline { 2 - 3 } & $2^{\circ}$ & 39 \\
\cline { 2 - 3 } & $3^{\circ}$ & 50 \\
\hline Total & & 150 \\
\hline
\end{tabular}

Todos os estudantes foram informados antecipadamente sobre os objetivos da pesquisa, participando de forma consciente e espontânea, sob prévia autorização e supervisão do corpo pedagógico da escola. Um termo de consentimento de livre esclarecimento foi assinado pelo próprio estudante quando maior de idade, ou pelos respectivos responsáveis, em caso de menores de idade.

A pesquisa foi realizada antes do início das atividades do projeto "Saberes da Mata Atlântica" e, portanto, os estudantes não receberam informações acerca do tema abordado. Para explicitar a percepção que os estudantes tinham sobre a Mata Atlântica, utilizou-se a técnica de evocação livre e um questionário semiestruturado. A evocação livre consiste na apresentação de uma palavra-estímulo ao respondente para que ele, por meio da associação livre, designe o objeto apresentado (SHIMIZU; MENIN, 2004). Nesta análise é possível avaliar quais palavras o sujeito mobiliza prontamente ao acionar sua estrutura cognitiva para dialogar com a palavra-estímulo, informada apenas no momento da avaliação. A palavra-estímulo utilizada foi "Mata Atlântica", sendo solicitado ao participante que escrevesse as 5 primeiras palavras que lhe viessem à mente ao ouvi-la. Os dados obtidos por meio da evocação livre foram submetidos à análise de conteúdo.

Bardin (2011) indica que a utilização da análise de conteúdo prevê três fases fundamentais: pré-análise, exploração do material e tratamento dos resultados.

A primeira fase, denominada de pré-análise, buscou atender às seguintes orientações:

obedecer às regras de exaustividade (deve-se esgotar a totalidade da comunicação, não omitir nada); representatividade (a amostra deve representar o universo); homogeneidade (os dados devem referir-se ao mesmo tema, serem obtidos por técnicas iguais e colhidos por indivíduos semelhantes); pertinência (os documentos precisam adaptar-se ao conteúdo e objetivo da pesquisa) e exclusividade (um elemento não deve ser classificado em mais de uma categoria) (CÂMARA, 2013, p. 183). 
$\mathrm{Na}$ segunda fase, ou fase de exploração do material, os dados foram examinados através de uma leitura simples, para categorização das respostas, contabilizando as informações em comum. $\mathrm{Na}$ terceira fase, denominada de tratamento dos resultados, foi feita uma análise qualitativa descritiva das respostas, interpretadas de modo a tornar os dados brutos significativos para os objetivos da pesquisa. Ao final das 3 etapas, identificou-se as categorias semânticas que emergiram do corpus da pesquisa e que auxiliaram na compreensão dos significados das palavras evocadas pelos participantes.

O questionário semiestruturado continha seis questões relacionadas a: (1) percentual de Mata Atlântica que ainda resta no Brasil, (2) regiões e estados abrangidos pela Mata Atlântica, (3) plantas nativas da Mata Atlântica, (4) animais nativos da Mata Atlântica, (5) principais impactos sobre a biodiversidade da Mata Atlântica no município, e (6) disciplinas escolares que abordam conteúdos relativos à Mata Atlântica. As questões fechadas do questionário foram analisadas por avaliação de frequência, as demais questões foram submetidas à análise de conteúdo. Para a avaliação da percepção sobre a conservação da Mata Atlântica foi solicitado que os estudantes marcassem qual o percentual de floresta remanescentes acreditavam restar no Brasil. Foram oferecidas as seguintes opções: $10 \%, 20 \%, 40 \%, 50 \%, 70 \%, 90 \%$ e extinta. $\mathrm{Na}$ avaliação da percepção dos estudantes sobre onde o bioma Mata Atlântica ocorre, foi solicitada a marcação dos estados dentro de um mapa do Brasil contendo suas unidades federativas. As questões sobre a percepção de flora e fauna do bioma abrangeram duas perguntas diretas, onde se solicitava que fossem registrados três nomes populares de plantas e de animais da Mata Atlântica. Para a análise da percepção dos estudantes sobre os impactos, solicitou-se a indicação de, ao menos, duas principais ameaças à biodiversidade do bioma. A última questão solicitou que marcassem quais disciplinas mais abordam conteúdos relativos à Mata Atlântica, sendo oferecidas as seguintes opções: ciências/biologia, história, geografia, português, matemática.

Inicialmente, realizou-se uma análise dos dados separadamente para cada nível de ensino e verificou-se a existência de um mesmo padrão e tendências nas percepções e conhecimentos. Sendo assim, realizou-se nova análise considerando todos os estudantes como pertencentes a um único grupo amostral.

Após a etapa de produção dos dados foi realizada uma intervenção pedagógica por meio das atividades do projeto "Saberes da Mata Atlântica" que, entre outras ações, realizou apresentação de vídeo e roda de conversa envolvendo a temática da pesquisa, tendo as perguntas do questionário como ponto de partida.

Todos os documentos produzidos a partir da presente pesquisa (entre eles, dados brutos, termos de autorização das escolas e de consentimento dos participantes ou responsáveis) estão arquivados no Laboratório de Biodiversidade do Departamento de Bioquímica e Biologia Molecular da Universidade Federal de Viçosa (MG).

revista brasileira educação ambiental 


\section{Resultados e Discussão}

\section{Representações cognitivas da Mata Atlântica}

O uso da técnica de evocação livre permitiu registrar 449 evocações a partir da palavra-estímulo "Mata Atlântica", distribuídas em 115 termos diferentes, os quais foram organizados em 11 categorias semânticas (Tabela 2). As categorias com maior frequência de evocação foram "flora" e "fauna" com $165(36,7 \%)$ e $103(22,9 \%)$ citações, respectivamente. As demais categorias identificadas foram: degradação, fatores abióticos, utilidade, cuidado, extensão, paisagem, contemplação e biodiversidade, cujas frequências estão dispostas na Tabela 2.

Tabela 2: Categorias semânticas que emergiram do corpus da pesquisa a partir da evocação livre de estudantes do ensino fundamental e médio a partir da palavra-estímulo "Mata Atlântica"

$$
(n=150)
$$

\begin{tabular}{|c|c|c|c|}
\hline Categoria & Exemplos de termos evocados & Total & $\%$ \\
\hline Flora & $\begin{array}{c}\text { Flora, mata, verde, árvores, plantas, florestas, flores, } \\
\text { vegetação. }\end{array}$ & 165 & 36,7 \\
\hline Fauna & Fauna, animais, insetos, pássaros, parasitas, predadores. & 103 & 22,9 \\
\hline Degradação & Desmatamento, extinção, caça, queimada. & 41 & 9,1 \\
\hline $\begin{array}{c}\text { Fatores } \\
\text { abióticos }\end{array}$ & Água, ar, solo, rochas, nascentes, chuva, rios, cachoeiras. & 38 & 8,5 \\
\hline Utilidade & $\begin{array}{c}\text { Frutas, plantas medicinais, trilhas, pesquisas, recursos } \\
\text { naturais, oxigênio, solo (para agricultura). }\end{array}$ & 26 & 5,8 \\
\hline Cuidado & Preservação, cuidar, proteção, não desmatar. & 24 & 5,4 \\
\hline Extensão & $\begin{array}{c}\text { Maior do mundo, maior do Brasil, maior bioma em extinção, } \\
\text { muito grande, extenso, vários estados. }\end{array}$ & 14 & 3,1 \\
\hline Outros & $\begin{array}{l}\text { Cultura, história, luta, greenpeace, evolução, perigo, } \\
\text { parques, localização. }\end{array}$ & 12 & 2,7 \\
\hline Paisagem & Relevos, paisagem, bioma. & 10 & 2,2 \\
\hline Contemplação & Beleza, paz, aromas, silêncio. & 10 & 2,2 \\
\hline Biodiversidade & Biodiversidade, diversidade, natureza, vida & 6 & 1,4 \\
\hline
\end{tabular}

Fonte: autoria própria.

As categorias reveladas pela evocação livre sugerem que, cognitivamente, os estudantes participantes da pesquisa percebem a Mata Atlântica como um ecossistema cujos elementos bióticos e abióticos precisam ser preservados, pois são recursos importantes para o homem. Não apareceu nas evocações elementos culturais que caracterizem o ambiente como espaço de cultura historicamente construída na relação homem-natureza. Nesse contexto, termos como cultura, história e luta foram citados apenas uma vez. Nota-se que as influências da Educação Ambiental construída sob a base do pensamento sistêmico/holístico persistem no cognitivo dos estudantes, seguindo-se a tendência conservadora presente no senso comum social. Para Layrargues e Lima (2014, p.30), 
[...] o conservacionismo e o conservadorismo, ao adotarem uma perspectiva com viés ecológico da questão ambiental, perdem de vista as dimensões sociais, políticas e culturais indissociáveis de sua gênese e dinâmica; porque não incorporam as posições de classe e as diferentes responsabilidades dos atores sociais enredados na crise; porque reduzem a complexidade do fenômeno ambiental a uma mera questão de inovação tecnológica e porque, finalmente, acreditam que os princípios do mercado são capazes de promover a transição no sentido da sustentabilidade.

Conforme registrado por Sauvé (2005), essa forma de perceber o meio ambiente, como sinônimo de natureza, tem como consequência a prática de uma Educação Ambiental cujo enfoque é apenas o aspecto cognitivo (aprender coisas sobre a natureza); experiencial (viver na natureza e aprender com ela); e afetivo, espiritual ou artístico (associando a criatividade humana à da natureza). Percebe-se, assim, o traço influente da proposta holística que tende a reificar, deificar ou sacralizar a natureza, retirando dela a dimensão humana em seu processo contínuo de transformação (LOUREIRO, 2006). Esse afastamento do homem e da natureza tem sua propagação continuada tanto pelos profissionais da educação quanto pela grande mídia, sendo essa, portanto, a percepção que, possivelmente, mais influencia os estudantes.

Dados de pesquisas obtidos por meio da evocação livre também têm sido analisados à luz da teoria das representações sociais, proposta por Serge Moscovici na década de 1960 e que se tornou uma das principais teorias da psicologia social (MOSCOVICl, 1989). Segundo Rateau e colaboradores (2012), a teoria das representações sociais explica que recorremos de uma forma automática à nossa estrutura cognitiva quando queremos explicar e entender o mundo ao nosso redor. Dessa forma, as representações sociais possuem uma estrutura denominada núcleo central, composta por elementos que são aqueles valores e princípios normalmente compartilhados por uma sociedade (MOSCOVICI, 1989). Isso explicaria a alta frequência de elementos naturais e a ausência de elementos culturais e políticos nas evocações livres dos estudantes participantes da presente pesquisa.

\section{Percepções dos estudantes sobre os remanescentes de Mata Atlântica no Brasil}

Quando questionados sobre qual percentual de Mata Atlântica ainda resta em nosso país, 49 estudantes $(32,6 \%)$ assinalaram que ainda restam $40 \%$ do bioma, $33(22 \%)$ responderam que ainda restam $70 \%$, e 20 deles $(13,3 \%)$ assinalaram que no Brasil há apenas $50 \%$ do bioma. Ainda, 3 estudantes (2\%) afirmaram que a Mata Atlântica compreende $90 \%$ da floresta original. Apenas 13 estudantes (8,6\%) indicaram um remanescente de $10 \%$ de floresta, porcentagem que mais se aproxima do valor de $12,4 \%$ indicado no Atlas da Mata Atlântica (SOS MATA ATLÂNTICA; INPE, 2019). Entre os 
respondentes, $3(2 \%)$ responderam que o bioma Mata Atlântica está extinto no Brasil e apenas um estudante não respondeu. A distribuição percentual das respostas sobre o total de remanescentes da Mata Atlântica no território brasileiro pode ser visualizada na Figura 1.

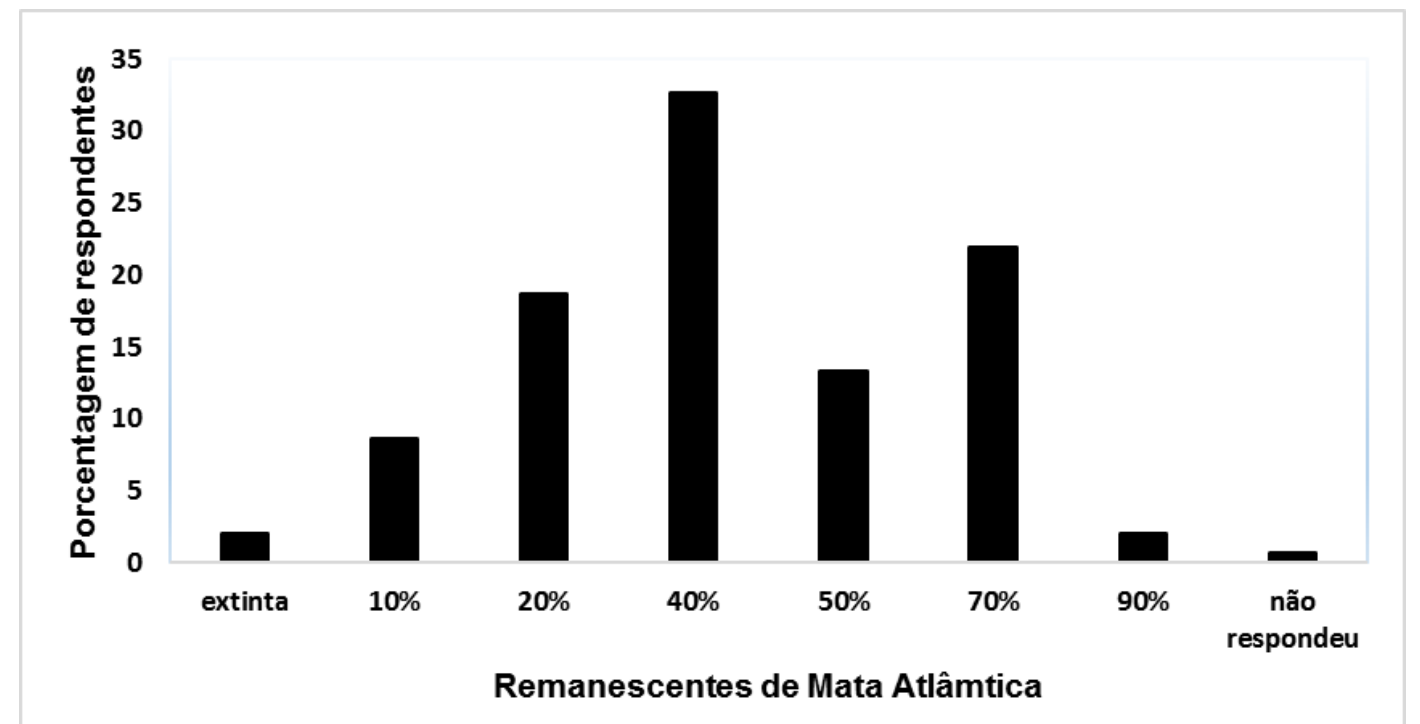

Figura 1: Distribuição percentual das respostas dos estudantes do ensino básico à pergunta "Qual o percentual de Mata Atlântica ainda resta no nosso país?" $(n=150)$

Fonte: autoria própria.

Uma das principais estratégias do processo de sensibilização da sociedade para a conservação da Mata Atlântica é a divulgação do percentual remanescente do bioma. Apesar da vulnerabilidade do bioma ser uma problemática debatida nos meios sociais, esta realidade não parece ser percebida pelos estudantes participantes da presente pesquisa. Nossos resultados mostram que grande parte deles superestima o percentual restante de Mata Atlântica no Brasil, aparentemente, não compreendendo a dimensão histórica das pressões antrópicas sofridas pelo bioma e a amplitude do avanço da urbanização sobre seu território.

\section{Percepção dos estudantes sobre a distribuição da Mata Atlântica}

Quanto à percepção dos estudantes sobre a distribuição do bioma Mata Atlântica no território nacional, obteve-se um total de 534 indicações. A região norte apresentou o maior percentual, $33,5 \%$. O estado do Amazonas foi o mais assinalado, com 92 indicações (que corresponde a $61,3 \%$ do total de estudantes participantes da pesquisa). Dentre as indicações para este estado, destacamos 29 estudantes (19,3\% do total) que assinalaram exclusivamente 0 Amazonas, não relacionando, portanto, a presença do bioma a mais nenhum outro estado brasileiro. Aparentemente, este resultado reflete uma tendência dos educandos em associar a Mata Atlântica à Floresta Amazônica (Tabela 3). No entanto, a região sudeste também obteve um número de indicações equivalente às da região norte, com $32,75 \%$, sendo o estado de Minas Gerais o 
mais assinalado, com 88 indicações (que corresponde a $58,6 \%$ do total de participantes). Contudo, apesar de reconhecerem a presença do bioma no estado de Minas, 37 estudantes assinalaram também o Amazonas ou outro estado da região Norte, o que demonstra que não há uma percepção dos limites da distribuição geográfica do bioma. A região Centro-Oeste obteve um total de $14,62 \%$ indicações, com destaque para o estado do Mato Grosso, assinalado por 41 estudantes (Tabela 3 ).

Tabela 3: Indicações de estudantes do ensino fundamental, médio e EJA sobre a distribuição da Mata Atlântica no território brasileiro.

\begin{tabular}{ccc}
\hline Região & Estados citados (número de citações) $\mathbf{n = 1 5 0}$ & $\begin{array}{c}\text { (\%) } \mathbf{n}= \\
\mathbf{5 3 4}\end{array}$ \\
\hline Norte & Acre (17), Amazonas (92), Pará (18), Rondônia (19), Amapá (7), & Tocantins (10), Roraima (16) \\
\hline Sudeste & $\begin{array}{c}\text { Espírito Santo (25), Rio de Janeiro (31), Minas Gerais (88), São Paulo } \\
(31)\end{array}$ & $32,7 \%$ \\
\hline $\begin{array}{c}\text { Centro- } \\
\text { Oeste }\end{array}$ & Mato Grosso (41), Mato Grosso do Sul (19), Goiás (15), Distrito Federal \\
\hline (2) & $14,6 \%$ \\
\hline Nordeste & $\begin{array}{c}\text { Ceará (2), Rio Grande do Norte (6), Paraíba (8), Pernambuco (8), } \\
\text { Alagoas (8), Sergipe (9), Bahia (5), Maranhão (10), Piauí (3) }\end{array}$ & $12,9 \%$ \\
\hline Sul & Paraná (14), Santa Catarina (11), Rio Grande do Sul (9) & $6,3 \%$ \\
\hline
\end{tabular}

Fonte: autoria própria.

O bioma Mata Atlântica abrange, total ou parcialmente, 17 estados brasileiros, sendo eles: Piauí, Ceará, Rio Grande do Norte, Paraíba, Pernambuco, Alagoas, Sergipe, Bahia, Espírito Santo, Rio de Janeiro, São Paulo, Minas Gerais, Goiás, Mato Grosso do Sul, Paraná, Santa Catarina e Rio Grande do Sul (SOSMA, 2011). O grande número de estudantes que não possuem uma percepção adequada da localização da Mata Atlântica é evidente, principalmente quando observamos o percentual de indicações dos estados das regiões norte e centro-oeste. No entanto, considerando que $58 \%$ dos estudantes indicaram o estado de Minas Gerais, compreendemos que, em parte, os resultados não refletem uma ausência total de percepção em relação à região onde vivem. Contudo, ainda há uma grande parcela dos estudantes que não compreende os limites de distribuição do bioma e 42\% não o associam à região da Serra do Brigadeiro. Aqui, vale lembrar as palavras de Grün (2002) ao afirmar que talvez a herança mais importante do cartesianismo, que reina nos métodos de ensino, é o fato de que com ele perdemos a noção de lugar, de pertencimento a um território, distanciando-se da ideia de lugar, como nos fala Cousin $(2013$, p. 8$)$ :

podemos considerar o lugar um conjunto de significados que foram construídos pela experiência. Ele é mais do que uma simples localização. Está carregado de signos e símbolos que resultam de um conjunto de sensações que foram moldadas pelas circunstâncias históricas, econômicas, políticas, sociais e culturais que os indivíduos experienciam e que apresentam um potencial de afetividade. 
Entendemos que a Educação Ambiental, em sua dimensão transdisciplinar, pode representar uma maneira de estimular uma compreensão menos cartesiana do espaço vivido e contribuir, assim, para a reconstrução da percepção geográfica desses estudantes. Neste contexto, a Educação Ambiental favorece a elaboração de uma ideia sobre o espaço que incorpora também a dimensão social e política. Ressalta-se, assim, a importância do ambiente escolar enquanto espaço privilegiado de formação, uma vez que tais conteúdos são próprios do currículo.

\section{Percepção dos estudantes sobre a flora da Mata Atlântica}

Quando questionados sobre nomes de plantas que ocorrem na Mata Atlântica, $34,6 \%$ dos estudantes não conseguiam recordar nenhum nome popular de plantas nativas do bioma ou citaram plantas exóticas. Dos que responderam, 27,3\% recordaram apenas uma espécie e 13,3\% indicaram duas espécies. Apenas $24,6 \%$ indicaram três ou mais plantas, conforme a questão solicitava. Foram registradas 192 citações de plantas nativas da Mata Atlântica, que correspondem a $75,6 \%$ do total de citações (Tabela 4). Neste grupo, as duas espécies da flora mais citadas foram o Pau-Brasil, com 72, e o Ipê, com 31. Dentre todas as citações, 24 correspondem a espécies exóticas, totalizando 9,5\%. Entre essas espécies destaca-se a Seringueira, com 15 citações.

Tabela 4: Plantas citadas por estudantes de ensino fundamental, médio e EJA como pertencentes ao bioma Mata Atlântica ( $n=216$ citações).

\begin{tabular}{ccc}
\hline Categoria & Espécies vegetais citadas (nome popular) & $\begin{array}{c}\text { Número e \% } \\
\text { de citações }\end{array}$ \\
\hline \multirow{4}{*}{ Nativas } & $\begin{array}{c}\text { Pau-Brasil (72), Ipê (31), Braúna (11), Embaúba (7), Canela (7), } \\
\text { Palmito (6), Pau-Jacaré (5), Jatobá (5), Orquídea (5), Jequitibá (4), } \\
\text { Quaresmeira (3), Pinheiro (3), Murici (3), Mata-Pau (2), Jacarandá } \\
\text { (2), Angico-Vermelho (2), Jambo (2), Aroeira (2), Caxeta (2), }\end{array}$ & 192 \\
& espécies nativas com uma citação apenas (18) & \\
\hline \multirow{2}{*}{ Exóticas } & Seringueira (15), Eucalipto (03), Castanheira (2), Mangueira (1), & 24 \\
& Coqueiro (1), Laranjeira (1), Cidreira (1) & $(11,1 \%)$ \\
\hline
\end{tabular}

Fonte: autoria própria.

A alta frequência de citação do Pau-Brasil pode ser explicada por se tratar de espécie ameaçada de extinção e frequentemente citada nas aulas de história como símbolo da exploração no período colonial. O Ipê possivelmente alcançou um grande número de citações (segundo mais citado) por ter uma florada marcante e de grande beleza. Entre as plantas exóticas citadas destacaram-se as de valor comercial como Seringueira e Eucalipto, que apesar de amplamente cultivadas na região sudeste, são originárias da bacia do Rio Amazonas e da Oceania, respectivamente. Outras espécies com valor econômico, de uso alimentício ou ornamental também estão presentes nas citações como a Canela, Palmito e Orquídea. 
Apesar das evidências sobre o conhecimento limitado dos estudantes acerca da Mata Atlântica quanto aos remanescentes e sua distribuição geográfica, ressalta-se como ponto positivo a predominância das plantas nativas nas respostas em detrimento das plantas exóticas. Nota-se, com isso, que os estudantes possuem conhecimentos etnobotânicos de sua região herdados, possivelmente, de seus familiares e também da vivência em proximidade com a natureza, típica de cidades do interior e com menor população da Zona da Mata mineira. Sob a ótica biorregionalista, esses conhecimentos devem ser valorizados, pois podem significar pontos de partida para a (re)construção do sentimento de pertencimento ao lugar. Sendo assim, o currículo das escolas do entorno do PESB não pode se furtar a responsabilidade de enfatizar os aspectos sociais, culturais, econômicos, políticos e ecológicos desse ambiente, bem como promover reflexões sobre as formas de representação desse bioma (QUARTEZANI; AGRIZZI; TEIXEIRA, 2016). Para Sato e Passos (2002) e Grün (2002), é através do biorregionalismo que esses conhecimentos podem ser inseridos no currículo.

\section{Percepção dos estudantes sobre a fauna da Mata Atlântica}

Quando perguntados sobre 3 nomes populares de animais nativos da Mata Atlântica, foram obtidas 367 citações, no entanto, 13 compreendiam espécies exóticas (Tabela 5). Entre as espécies de animais mais citadas, encontramos um protagonismo dos mamíferos, com destaque para felinos e macacos, com 95 e 76 indicações, respectivamente. Observa-se um destaque para as espécies ameaçadas de extinção, como Onça e Mico-Leão-Dourado. As aves também se destacaram, com 60 citações, sendo também principalmente indicadas espécies ameaçadas, como a Arara-Azul. Entre as espécies exóticas, estão citações de animais da fauna africana e asiática, como Leão e Tigre, respectivamente. Um total de 17 estudantes não responderam à questão.

Tabela 5: Animais que habitam o bioma Mata Atlântica indicados por estudantes da educação básica $(n=150)$. Devido ao volume de citações, alguns animais foram agrupados para apresentação na tabela (ex.: felinos, macacos, pássaros, etc.)

\begin{tabular}{clc}
\hline Categoria & \multicolumn{1}{c}{ Grupos taxonômicos citados (nome popular) } & $\begin{array}{c}\text { Total de citações/ } \\
\%(\mathbf{n = 3 6 7 )}\end{array}$ \\
\hline \multirow{3}{*}{ Nativas } & Felinos (95), Macacos (76), Pássaros (60), Cobras (51), Lobo & \\
& $\begin{array}{l}\text { (12), Lagarto (9), Jacaré (8), Tamanduá (8), Tatu (8), Insetos } \\
\text { (8), Preguiça (5), Sapo (4), Veado (3), Capivara (3), Gambá }\end{array}$ & 354 \\
& & $(95,7 \%)$ \\
\hline \multirow{2}{*}{ Exóticas } & Leão (5), Crocodilo (2), Cavalo (1), Gado (1), Chimpanzé (1), & 13 \\
& Tigre (1), Diabo da Tasmânia (1), Furão (1). & $(2,7 \%)$ \\
\hline
\end{tabular}

Fonte: autoria própria.

Sabe-se que a percepção dos estudantes tem sido fortemente influenciada pela grande mídia, que privilegia mamíferos e aves nas campanhas de conservação. Estes grupos de animais são apresentados 
frequentemente como símbolos de conservação da biodiversidade (PARIS et al., 2014). Possivelmente, isso explique a predominância desses grupos taxonômicos nas respostas dos estudantes quando perguntados sobre as espécies da fauna da Mata Atlântica.

Dentre as citações de espécies de macacos, obtiveram-se 17 referências ao Muriqui. Maior primata das Américas, extremamente ameaçado, e exclusivo da Mata Atlântica, o Muriqui tem no PESB uma de suas maiores populações (STRIER, 2017; STRIER et al., 2017). Diante dos projetos de pesquisa e ações de Educação Ambiental de apelo à sua conservação na região, consideramos reduzido o número de citações da espécie. Esse resultado pode ser um indicativo de que as propostas pedagógicas desses projetos não têm alcançado seus objetivos. Além disso, na perspectiva biorregionalista, pode-se inferir que uma Educação Ambiental com foco exclusivo na conservação de espécies e desconectadas dos aspectos culturais não produz os efeitos desejados, uma vez que não ressignifica as relações homem-natureza.

\section{Percepção dos estudantes sobre os principais impactos sobre a biodiversidade da Mata Atlântica}

Quando perguntados sobre quais os principais impactos sobre a biodiversidade da Mata Atlântica, obtivemos um total de 139 citações. Do total de 150 estudantes, 13 não responderam. Dentre as citações, a mais frequente foi o desmatamento, com 52 referências $(37,4 \%)$, seguida por queimadas com $31(22,3 \%)$ (Tabela 6). Poluição e caça também foram mencionadas, com 10,8 e $9,3 \%$, respectivamente. Homem e extinção obtiveram o mesmo número de citações.

Tabela 6: Principais impactos sobre a biodiversidade da Mata Atlântica indicados por estudantes de escolas do entorno do PESB ( $n=150$ estudantes)

\begin{tabular}{ccc} 
Categoria & Número de citações $(\mathbf{n}=\mathbf{1 3 9})$ & $\%$ \\
\hline Desmatamento & 52 & 37,4 \\
\hline Queimadas & 31 & 22,3 \\
\hline Poluição & 15 & 10,8 \\
\hline Caça & 13 & 9,3 \\
\hline Homem & 05 & 3,6 \\
\hline Extinção & 05 & 3,6 \\
\hline Outros & 07 & 5,0 \\
\hline Não responderam & 13 & 8,7 \\
\hline
\end{tabular}

Fonte: autoria própria.

$\mathrm{Na}$ Tabela 6, foram agrupados na categoria "Outros" ameaças à biodiversidade da Mata Atlântica que foram citadas uma única vez, entre elas: agronegócio, mineração e extinção de espécies. 
O agronegócio e a expansão urbana representam atualmente as principais ameaças à Mata Atlântica e à sua biodiversidade (SILVA et al., 2016). Nesse contexto, entre as ações que contribuem nesses processos estão o desmatamento e as queimadas. Portanto, os resultados obtidos evidenciam uma percepção dos estudantes compatível com os impactos reais sofridos pelo bioma. No entanto, ao analisarmos os percentuais de citações, compreendemos que uma parcela reduzida dos estudantes percebe essas ações humanas como sendo as principais ameaças à biodiversidade, o que indica um olhar distante da realidade. Araújo e Sovierzozki (2016) também evidenciaram que grande parte dos estudantes da região nordeste brasileira não compreendem quais os principais impactos sofridos pelos biomas Mata Atlântica e Caatinga. Portanto, tomando-se a perspectiva biorregionalista como referência, os resultados obtidos no presente estudo reforçam a necessidade de uma Educação Ambiental e científica que, por meio da valorização dos aspectos socioambientais e da história do lugar, possam ressignificar as relações entre a comunidade e o ambiente (OLIVEIRA JUNIOR; SATO, 2006, p. 130).

\section{Percepção dos estudantes sobre a abordagem dos conteúdos da Mata Atlântica no currículo escolar}

$\mathrm{Na}$ questão sobre quais disciplinas já abordaram temáticas relativas à Mata Atlântica, a disciplina de ciências/biologia teve 53,1\% das indicações, seguida de geografia com $41,1 \%$. As disciplinas de história, matemática e português também receberam indicações com 3,5\%, 1,1\% e $0,6 \%$, respectivamente. Esses resultados corroboram o que afirmam Nunes, França e Paiva (2017), quando dizem que a Educação Ambiental nas escolas ainda é superficial e pontual, normalmente se restringindo às disciplinas de ciências, biologia e geografia, ou a eventos comemorativos como o "Dia do Meio Ambiente".

Aqui, ressalta-se a importância da Educação Ambiental em ambientes formais, pois a diversificação do currículo e a problematização das questões do cotidiano a partir do bioma Mata Atlântica enquanto biorregião, é papel de todos os professores e deve ser abordada, preferencialmente, de forma interdisciplinar e transversal (QUARTEZANI; AGRIZZI; TEIXEIRA, 2016). Nesse sentido, Segura (2001, p.195) defende que "se a escola conseguir propiciar uma leitura crítica da realidade, agregando diversos conhecimentos a ela relacionados, [...] estará cumprindo seu papel na formação de consciência ambiental". 


\section{Considerações Finais}

Os estudantes da educação básica das quatro escolas do entorno do PESB demonstraram conhecimentos equivocados, do ponto de vista do saber científico, sobre temas relativos à Mata Atlântica, os quais, via de regra, são conteúdos integrantes do currículo escolar. Especificamente, verificou-se a existência de uma percepção quanto à distribuição geográfica do bioma, que se distancia do que tem sido divulgado pela ciência, revelando, inclusive, uma confusão entre Mata Atlântica e Floresta Amazônica por parte de uma parcela dos estudantes. Além disso, verificou-se uma limitação na percepção de componentes da fauna e flora local, bem como de seu estágio de conservação.

Diante dos resultados obtidos, pondera-se sobre a importância da implementação de atividades pedagógicas no currículo das escolas da região que busquem estabelecer uma conexão entre a comunidade local e os ambientes de Mata Atlântica da região, explorando-se seu aspecto interdisciplinar. É preciso abordar os aspectos socioculturais do bioma, especialmente relacionando-os ao contexto histórico do desenvolvimento da biorregião, conteúdos afeitos às disciplinas de geografia e história.

Considerando-se que a vivência com a natureza é primordial para o processo de ressignificação da percepção acerca de questões ambientais, é importante $o$ fortalecimento da parceria entre escolas e Unidades de Conservação. No entanto, destacamos a necessidade de um planejamento conjunto que dialogue com o projeto pedagógico da escola e que não se limite a ações pontuais.

Os resultados do presente estudo reforçam a importância da Educação Ambiental e divulgação científica, especialmente em sua abordagem crítica em associação com o biorregionalismo. Além disso, evidenciam que a compreensão da percepção ambiental e científica dos estudantes constitui uma importante ferramenta para o planejamento das atividades do projeto "Saberes da Mata Atlântica", uma vez que possibilita estabelecer metodologias pedagógicas adequadas à realidade local.

Finalmente, propõe-se uma educação capaz de proporcionar uma formação para além dos aspectos físicos do ambiente, contribuindo para a (re)construção de uma percepção mais significativa da realidade, do sentimento de pertencimento ao lugar e para o exercício da cidadania.

\section{Agradecimentos}

À Fundação de Amparo à Pesquisa do Estado de Minas Gerais (FAPEMIG) pelo apoio financeiro através do Edital de Popularização da Ciência, da Tecnologia e da Inovação.

Aos gestores, educadores e estudantes das escolas do entorno do PESB, pela recepção e acolhimento ao Projeto "Saberes da Mata Atlântica". 
Ao Instituto Estadual de Floresta de Minas Gerais e ao Parque Estadual da Serra do Brigadeiro pelo apoio na logística das expedições nos municípios.

À Pró-Reitoria de Extensão e Cultura da UFV pela disponibilização do Caminhão da Ciência e de funcionários de apoio técnico.

\section{Referências}

ARAÚJO, B. F.; SOVIERZOSKI, H. H. Percepção dos alunos do ensino médio sobre os biomas de mata atlântica e caatinga. Revista Práxis, Volta Redonda, v. 8, n. 16, p. 81-94, dezembro 2016.

BARDIN, L. Análise de Conteúdo. São Paulo: Edições 70, 2011.

BRASIL. Constituição da República Federativa do Brasil de 1988. Disponível

em:

$<$ http://www.planalto.gov.br/ccivil 03/constituicao/constituicao.htm>. Acesso em: 03 mar. 2020.

BRASIL. Decreto no $^{\circ} \mathbf{2 8 1}$ de 25 de junho de 2002. Disponível em: <http://www.planalto.gov.br/ccivil 03/decreto/2002/D4281.htm>. Acesso em: 23 mar. 2020.

BRASIL. Política Nacional de Educação Ambiental. Lei 9.795/99. Brasília, DF, 1999. Lei $n^{\circ}$ 9.795, de 27 de abril de 1999. Dispõe sobre a Educação Ambiental, institui a política nacional de Educação Ambiental e dá outras providências. Disponível em: <http://www.planalto.gov.br/ccivil 03/LEIS/L9795.html>. Acesso: 09 dez. 2019.

BRASIL. Sistema Nacional de Unidades de Conservação da Natureza SNUC, 2000. 32 p. Disponível em: <https://www.mma.gov.br/areasprotegidas/unidades-de-conservacao/sistema-nacional-de-ucs-snuc.html>.

Acesso em: 20 mar. 2020.

CÂMARA, R. H. Análise de Conteúdo: da teoria à prática em pesquisas sociais aplicadas às organizações. Gerais: Revista Interinstitucional de Psicologia, v. 6, n. 2, p. 179-191, 2013.

COUSIN, C. S. Pertencimento ao lugar e a formação de educadores ambientais: um diálogo necessário. Anais do VII EPEA - Encontro Pesquisa em Educação Ambiental Rio Claro - SP, p. 1-15, 2013.

COUSIN, C. S. Trilhas e itinerários da Educação Ambiental nos trabalhos de campo de uma comunidade de aprendizagem. 2004. 143f. Dissertação: (Mestrado em Educação Ambiental), Fundação Universidade Federal do Rio Grande - FURG, Rio Grande.

CRESWELL, J. W. Métodos qualitativo, quantitativo e misto. Porto Alegre. Artmed. 2010. $296 \mathrm{p}$.

DEAN, W. A Ferro e Fogo: a história e a devastação da mata atlântica brasileira. 1aㅡ ed. São Paulo: Cia. das Letras, 2004. 484 p. 
DIAS, G. F. Educação Ambiental: princípios e práticas. 9a ed. São Paulo: Gaia, 2004. 552 p.

EISENLOHR, P.V. et al. Disturbances, elevation, topography and spatial proximity drive vegetation patterns along an altitudinal gradient of a top biodiversity hotspot. Biodiversity and Conservation, v. 22, n. 12, p. 27672783, 2013.

FERNANDES, R.S.; SOUZA, V.J.; PELISSARI, V.B.; FERNANDES, S.T. Uso da Percepção Ambiental Como Instrumento de Gestão em Aplicações Ligadas às Áreas Educacional, Social e Ambiental. São Paulo: 2004. Disponível em: http://143.106.158.7/anppas/encontro2/GT/GT10/roosevelt fernandes.pdf>. Acesso em: 21 jan. 2020.

FUNDAÇÃO SOS MATA ATLÂNTICA. Novos Dados do Atlas da Mata Atlântica. 2011. Disponível em: <https://www.sosma.org.br/noticias/novosdados-do-atlas-da-mata-atlantica/>. Acesso em: 11 mar. 2020.

GONZÁLEZ, S. Educação Ambiental Biorregional: a comunidade aprendente na ilha das Caieiras, vitória (es). Dissertação: (Programa de Pós-Graduação em Educação). Universidade Federal do Espírito Santo, Vitória, ES, 2006.

GRÜN, M. Hermenêutica, Biorregionalismo e Educação Ambiental. In: SAUVÉ, L. et al., Textos escolhidos em Educação Ambiental - de uma América à outra. Quebec: Les Publications ERE-UQAN, Tomo I. p. 91-99. 2002.

INSTITUTO ESTADUAL DE FLORESTA. Parque Estadual da Serra do Brigadeiro. 2020. Disponível em: <http://www.ief.mg.gov.br/ component/content/197?task=view>. Acesso em: 11/03/2020.

JOLY, C. A.; METZGER, J. P.; TABARELLI, M. Experiences from the Brazilian Atlantic Forest: ecological finding sand conservation initiatives. New Phytologist, v. 204, n. 3, p. 459- 473, 2014.

LAYRARGUES, P.P.; LIMA, G.F.C. As Macrotendências Político-Pedagógica da Educação Ambiental Brasileira. Ambiente \& Sociedade. São Paulo, v. XVII, n. 1, 2014, p. 30.

LOUREIRO, C. F. B. Complexidade e Dialética: contribuições à práxis política e emancipatória em Educação Ambiental. Educ. Soc., Campinas, v. 27, n. 94, p. 131-152, 2006.

MOSCOVICI, S. Des Représentations Collectives aux Représentations Sociales. In: JODELET, D. (org.), Les Représentations Sociales. Paris, Press Universitary de France, 1989.

MYERS, N. et al. Biodiversity Hotspots for Conservation Priorities. Nature, v. 403, n. 6772, p. 853-858, 2000.

NUNES, M.E.R.; FRANÇA, L.F.; PAIVA, L.V. Eficácia de Diferentes Estratégias no Ensino de Educação Ambiental: associação entre pesquisa e extensão universitária. Ambiente \& Sociedade. São Paulo, v. 20, n. 2, p. 61-78, 2017. 
OLIVEIRA-FILHO, A.T.; FONTES, M.A.L. Patterns of Floristic Differentiation Among Atlantic Forests in South Eastern Brazil and the Influence of Climate. Biotropica, v. 32, n. 4b, p. 793-810, 2000.

OLIVEIRA JUNIOR, S.B.; SATO, M. Educação Ambiental e Etnoconhecimento: parceiros para a conservação da diversidade de aves pantaneiras. Ambiente e Educação, v. 11, p. 125-137, 2006.

POLIT, D.F.; BECK, C.T.; HUNGLER, B.P. Fundamentos de Pesquisa em Enfermagem: métodos, avaliação e utilização. Trad. de Ana Thorell. 5a ed. Porto Alegre: Artmed, 2004, $487 \mathrm{p}$.

QUATERZANI, H.S.; AGRIZZI, A.P.; TEIXEIRA, M.C. O Que os Estudantes das Escolas das Restingas dizem sobre "Restinga"? um olhar biorregionalista sobre o ensino de ciências das escolas do distrito de guriri, es. Revista da SBEnbio, n. 9. p. 7553-7564, 2016.

RATEAU, P.; MOLINER, P.; GUIMELLI, C.; ABRIC, J.C. Teoria das Representações Sociais. Handbook of Theories of Social Psychology. v. 2, p. 477- 497, 2012.

REIGOTA, M. Meio Ambiente e Representação Social. São Paulo: Cortez, 1995. $87 \mathrm{p}$.

RIBEIRO, M.; METZGER, J.P.; MARTENSEN, A.C.; PONZONI, F.J.; HIROTA, M.M. The Brazilian Atlantic Forest: how much is left, and how is the remaining forest distributed? implications for conservation. Biological Conservation. v.142, p.1141-1153, 2009.

RIBEIRO, M.C. et al. The Brazilian Atlantic Forest: a shrinking biodiversity hotspot. Biodiversity Hotspots, p. 405-434, 2011.

RIO, V.; OLIVEIRA, L. (Orgs.). Percepção Ambiental. a experiência brasileira. $2^{a}$ ed. São Paulo, Studio Nobel, 1999. 270 p.

SATO, M.; PASSOS, L. A. Biorregionalismo: identidade histórica e caminhos para a cidadania. In: LOUREIRO, L.F.; LAYARGUES, P.; CASTRO, R.S. (orgs.), Educação Ambiental: repensando o espaço da cidadania. Cortez, São Paulo, p. 221-252, 2002.

SAUVÉ, L. Uma Cartografia das Correntes em Educação Ambiental. Educação Ambiental: pesquisa e desafios, p. 17-44, 2005.

SEGURA, D. S. B. Educação Ambiental na Escola Pública: da curiosidade ingênua à consciência crítica. São Paulo: Annablume, Fapesp, 2001. 214 p.

SHIMIZU, A. M.; MENIN, M.S.S. Representações Sociais de Lei, Justiça e Injustiça: uma pesquisa com jovens argentinos e brasileiros utilizando a técnica de evocação livre de palavras. Estudos de Psicologia. Natal. v. 9, n. 2, p.239247, 2004.

SILVA, J.M.C.; CASTELETI, C.H.M. Status of the Biodiversity of the Atlantic Forest of Brazil. the atlantic forest of south america: biodiversity status, threats, and outlook - CABS and Island Press, p. 43-59, 2003. 
SILVA, J.M.C.; PINTO, L.P.; HIROTA, M; BEDÊ, L.; TABARELLI, M. Conservação da Mata Atlântica Brasileira: um balanço dos últimos dez anos. In.: CABRAL, D.C.; BUSTAMANTE, A.G. (Orgs). Metamorfoses Florestais: culturas, ecologias e as transformações históricas da mata atlântica. Prismas. 2016, $458 \mathrm{p}$.

SOS Mata Atlântica e INPE. Atlas dos Remanescentes Florestais da Mata Atlântica: período 2017-2018, São Paulo (2019). Disponível em: $<$ https://www.sosma.org.br/wp-content/uploads/2019/05/Atlas-mataatlantica 17-18.pdf>. Acesso em: 30 mar. 2020.

STRIER. K.B. The International Encyclopedia of Primatology, Wiley Online Library, $2017 . \quad$ Disponível em: $<$ https://onlinelibrary.wiley.com/doi/book/10.1002/9781119179313>. Acessado em: 05 abr. 2020.

STRIER, K.B.; POSSAMAI, C.B.; TABACOW, F.P.; PISSINATTI. A.; LANNA, A.M.; DE MELO, F.R. et al. Demographic Monitoring of Wild Muriqui Populations: criteria for defining priority areas and monitoring intensity. 2017. PLOS ONE. Disponível em: <https://doi.org/10.1371/journal.pone.0188922>. Acessado em: 05 abr. 2020.

UNESCO. Carta de Belgrado: uma estrutura global para a Educação Ambiental. Belgrado: UNESCO, 1975. Disponível em: $<$ https://www.mma.gov.br/informma/item/8066-carta-de-belgrado>. Acesso em: 08 mar. 2020. 